\title{
La acción de nulidad de un laudo arbitral: ¿un proceso de conocimiento?
}

\author{
Fausto Albuja Guarderas*
}

\begin{abstract}
SUMARIO: 1. Sobre la acción de nulidad. 2. Sobre los procesos de conocimiento. 3. Sobre las decisiones de la Corte. 4. Consideraciones finales.
\end{abstract}

\section{Sobre la acción de nulidad}

No es desconocido que la acción de nulidad ${ }^{1}$ constituye una forma de control judicial de un laudo arbitral, limitada a cinco causales ${ }^{2}$. Las mismas se encuentran establecidas en el artículo 31 de la Ley de Arbitraje y Mediación y buscan fundamentalmente que se respete el debido proceso y la seguridad jurídica. El juez que conoce la acción de nulidad no puede resolver sobre el fondo de la controversia arbitral. No está por demás recordar que el juicio arbitral es de única instancia.

El mencionado artículo 31, sufrió una importante reforma en el año 2005. En efecto: i) se incluyó una nueva causal de nulidad, ii) se estableció un trámite especial y sumario para ésta acción, señalando como juez competente

\footnotetext{
* Licenciado en Ciencias Jurídicas y Abogado por la Universidad Católica del Ecuador, Magister en Derecho de Empresa por la Universidad San Francisco de Quito. Está facultado para ejercer la abogacía en todos los Tribunales de la República del Ecuador. Actualmente, se encuentra desempeñando el cargo de Subdirector de Arbitraje Nacional, en la Procuraduría General del Estado. Previamente a ingresar al sector público, ejerció libremente la profesión en el ámbito privado, representando a importantes compañías locales. También, se desempeña como profesor en a Universidad de las Américas desde el año 2007.

1. El Dr. J. M. MARCHÁN en su artículo, "La aplicación de la acción de nulidad de laudos arbitrales en el Ecuador", publicado en la Revista Ecuatoriana de Arbitraje 2011, recoge varias sentencias que de alguna forma establecen el objetivo de la acción de nulidad. Me permito rescatar aquellas que señalan: "Las características principales de la acción de nulidad es que es una acción extraordinaria y limitada por decisión del legislador, que ha sido concebida como un mecanismo de control judicial del procedimiento arbitral, mas no como una vía para acceder a una instancia que revise integralmente la controversia resuelta por el laudo...."

2. Se ha discutido en el foro arbitral si la falta de solicitud de la interpretación prejudicial al Tribunal Andino de Justicia, en los casos que lo amerite, constituye una causal de nulidad de laudo arbitral. Por otro lado, es pertinente considerar lo dispuesto en el literal l) del numeral 7 del artículo 76 de la Constitución que dispone la nulidad de las resoluciones o fallos que no se encontraren debidamente motivados. En este último caso, podría plantearse la inquietud en relación a si es procedente plantear una acción de nulidad que busque declarar la nulidad por falta de motivación o interponer directamente una acción extraordinaria de protección en contra del laudo
} 
para conocerla al presidente de la Corte Provincial de Justicia. Previamente a la reforma la norma disponía que el presidente de creerlo pertinente podía ordenar el sorteo de la causa para que ésta sea conocida y tramitada por una de las Salas de dicha Corte; y, iii) se sustituyó el término "recurso" por el de "acción".

Llamamos la atención sobre esta reforma pues más allá de los aspectos relevantes que contuvo, hay uno que es pertinente para efectos de este documento y tiene que ver con el hecho de que se dejó claro que la acción de nulidad es tal y no un recurso ${ }^{3}$.

La parte pertinente del texto de la norma antes de la reforma señalaba:

Cualquiera de las partes podrá intentar la acción de nulidad de un laudo arbitral, cuando:

[...] Este recurso se interpondrá ante el tribunal que conoció la causa y éste, a su vez, sin pronunciarse sobre la procedencia o improcedencia del mismo, remitirá el proceso al Presidente de la Corte Superior del Distrito del lugar del arbitraje para que conozca el recurso, dentro del término de tres días después de interpuesto.

[...] Quien interponga el recurso de nulidad, podrá solicitar a los árbitros que se suspenda la ejecución del laudo, rindiendo caución suficiente sobre los perjuicios estimados que la demora en la ejecución del laudo pueda causar a la otra parte.

[...] El recurso de nulidad podrá interponerse dentro del término de diez días contados desde la fecha de la notificación del laudo" ${ }^{4}$. (El énfasis me corresponde)

3. El profesor H. Devis ECHANDiA, en su obra "Compendio de Derecho Procesal, tomo I, Teoría General del Proceso” (p. 167) define a la acción como “...el derecho público, cívico, subjetivo, abstracto y autónomo, que tiene toda persona natural o jurídica, para obtener la aplicación de la jurisdicción del Estado a un caso concreto mediante una sentencia, a través de un proceso."Así mismo, el autor define al recurso (p. 505) como "la petición formulada por una de las partes, principales o secundarias, para que el mismo juez que profirió una providencia o su superior la revise con el fin de corregir los errores de juicio o de procedimiento (in judicando o in procedendo) que en ella se hayan cometido".

4. Parte del texto del artículo 31 de la Ley de Arbitraje y Mediación antes de la reforma del 25 de febrero de 2005, publicada en el Registro Oficial No. 532 de 25 de febrero del 2005. 
Actualmente dispone:

Del laudo arbitral podrá interponerse ante el árbitro o tribunal arbitral, acción de nulidad para el respectivo presidente de la corte superior de Justicia, en el término de diez días contado desde la fecha en que se ejecutorió. Presentada la acción de nulidad, el árbitro o tribunal arbitral, dentro del término de tres días, remitirán el proceso al presidente de la corte superior de justicia, quien resolverá la acción de nulidad dentro del término de treinta días contados desde la fecha que avocó conocimiento de la causa. La acción de nulidad presentada fuera del término señalado, se tendrá por no interpuesta y no se la aceptará a trámite 5 . (El énfasis me corresponde).

Previamente a la reforma podía existir una confusión en cuanto a si la nulidad de un laudo arbitral constituía una acción o un recurso, pues como vimos la norma utilizaba los dos términos indistintamente. Sin embargo, a partir de la reforma no es correcto insistir en que dicha acción constituye un recurso más allá de que se lo califique como "incidental". Es importante señalar que esta no es la única razón por la cual no podría considerase a la acción de nulidad como un recurso. Como acertadamente lo señala el Dr. Xavier ANDRADE CADEna hay otros motivos que sustentan esta posición, a saber: i) la Ley prohíbe la posibilidad de interponer cualquier clase de recurso en contra del laudo arbitral (salvo la aclaración o la ampliación) por contravenir la naturaleza misma del arbitraje, ii) la Corte Provincial no puede resolver sobre el fondo de la controversia, únicamente debe limitarse a declarar la nulidad o no del laudo, iii) no puede ser considerado un recurso de apelación pues la Corte Provincial no es un órgano jerárquicamente superior a un tribunal arbitral, iv) las partes decidieron que sea un árbitro o tribunal arbitral quien resuelva su controversia sin que esta facultad -señala ANDRADE- pueda ser trasmitida vía recurso a la justicia ordinaria; y, v) el arbitraje es de instancia única ${ }^{6}$.

Las causales de nulidad, como lo hemos señalado, tienen por objetivo fundamentalmente precautelar la garantía al debido proceso en lo que tiene que ver con el derecho a la defensa y la debida motivación, así como, la seguridad jurídica. En efecto, estas circunstancias se evidencian al revi-

5. Segundo inciso del artículo 31 de la Ley de Arbitraje y Mediación a partir de la reforma a dicha ley, publicada en el Registro Oficial No. 532 de 25 de febrero del 2005.

6. www.andradeveloz.com/newSite/descargas/publicaciones/nulidad_de_laudos_arbitrales.pdf 
sarlas, pues, disponen que el laudo será nulo en los casos en los que no se haya citado correctamente al demandado, en aquellos en que no haya sido notificada cualquiera de las partes con las providencias dictadas por el tribunal arbitral, en los que no se haya convocado, no se hubiere notificado la convocatoria, o si fue convocado no se hubieren practicado las pruebas, en todos los casos en los que se resuelva sobre cuestiones no sometidas al arbitraje o se conceda más allá de lo reclamado; $y$, cuando se violaron los procedimientos establecidos por la ley o por las partes para la designación de árbitros o constitución del tribunal arbitral.

El procedimiento de la acción de nulidad es especial 7 , ésta debe ser presentada ante el árbitro o tribunal que dictó el laudo, dentro del término de diez días desde la fecha en que se ejecutorió el laudo; a su vez, dichos árbitros o tribunal deben remitir el proceso al presidente de la Corte Provincial quien conocerá y resolverá la causa dentro del término de treinta días desde la fecha en que avocó conocimiento de la misma.

Hemos podido revisar varios casos en la ciudad de Quito y establecer que en la práctica la demanda que contiene la acción de nulidad debe incluir los requisitos que señala la ley para estos efectos. El juez que conoce la causa ordena se cite al o los demandados a fin de que contesten la demanda. Incluso en varios casos, el juez otorga el término de ocho días ${ }^{8}$ para contestarla. Con la contestación y sin otro trámite se dicta sentencia. Es posible solicitar una audiencia de estrados para alegar en derecho. Lo dicho podría llevarnos a la conclusión de que los señores jueces han definido que la acción de nulidad constituye un verdadero juicio?.

En relación con la posibilidad de recurrir a la sentencia, la Presidencia de la Corte Provincial de Pichincha ${ }^{10}$, ha aceptado recursos de apelación planteados en contra de sus sentencias, recursos que han sido conocidos y resueltos por la Sala de lo Civil y Mercantil de dicha Corte. De las resoluciones dictadas por esta Sala, hemos revisado que en varios casos se ha

7. Resolución de la Corte Constitucional No. 8, Registro Oficial, Suplemento 605 de 4 de junio de 2009. En esta resolución se deja claro que el trámite de la acción de nulidad es especial. Hemos encontrado varios casos, especialmente de años anteriores al 2005, en que los jueces disponían que el trámite que debía seguirse en esta clase de acciones era el ordinario.

8. Juicio Especial de Nulidad de Laudo Arbitral No. 04-2012.

9. El artículo 57 del Código de Procedimiento Civil dispone: "Juicio es la contienda legal sometida a la resolución de los jueces".

10. Juicios Especiales de Nulidad de Laudo Arbitral Nos. 05-2013 y 44-2012. 
planteado recursos de casación, los mismos que han sido aceptados ${ }^{11}$ por ellas y negados por la Sala de Admisiones de la Corte Nacional, sobre esto último volveremos más adelante. Debemos indicar que también hemos observado casos en que la Sala de lo Civil y Mercantil de la Corte Provincial ha negado recursos de casación presentados en contra de sus sentencias, dictadas en procesos de nulidad de laudos arbitrales ${ }^{12}$.

La acción de nulidad constituye; i) un proceso nuevo que nace a partir de que se ha dictado un laudo, ii) es independiente del proceso arbitral del cual surgió, y iii):

[...] obliga al juez con jurisdicción legal, a ejercer su facultad de examinar de un modo concreto y no abstracto en un proceso arbitral singular, si el tribunal de arbitraje ha cumplido con el deber de conducir y resolver la causa con sujeción estricta a lo convenido por las partes y a lo preceptuado por la ley, para garantizar el debido proceso. Con la resolución que dicte al haberse planteado la acción de nulidad, el juez no resta capacidad al sistema arbitral, cuando declara la nulidad, sino que obliga a que los árbitros actúen con la extremada diligencia que la misión de juzgar, porque las partes así le han convenido, les impone ${ }^{13}$.

Señalamos que es un nuevo proceso e independiente del arbitral pues: i) la acción de nulidad no es un acto del proceso arbitral, dado que éste termina con la expedición del laudo, sobre el cual es únicamente posible

11. Juicios Especiales de Nulidad de Laudo Arbitral Nos. 17113-2014-1364, 17113-2014-3652.

12. El argumento que han sostenido para esta negativa ha sido el siguiente: "La sentencia objeto del recurso no proviene de un juicio de conocimiento, conforme exige inflexiblemente el Art. 2 de la Codificación a la Ley de Casación, particular establecido en Jurisprudencia publicada en la Gaceta Judicial. Año CII. Serie XVII. No. 7. Página 1909, en resolución dictada el 10 de octubre de 2001, la cual en su parte pertinente en forma radical sostiene: «... la impugnación de un laudo arbitral no es un asunto de conocimiento, en atención a lo prescrito en el Art. 32 de la Ley de Arbitraje y Mediación. El arbitraje es un mecanismo de solución de conflictos de jurisdicción privada por terceras personas, que no tienen la calidad e investidura de los jueces de la jurisdicción común, previo sometimiento voluntario de las partes en tal decisión, y cuya existencia impide a la Función Judicial conocer sobre las cuestiones litigiosas sometidas al arbitraje. Así la disposición del Art. 31 de la Ley de Mediación y Arbitraje estatuye la inapelabilidad del laudo arbitral, por lo que la decisión arbitral se torna irrevocable, y podrá obtenerse su ejecución forzada del mismo modo que las sentencias de última instancia, siguiendo la vía de apremio». Criterio vigente, obligatorio y concordante con la Ley de Arbitraje y Mediación que en su artículo 30, inciso segundo, establece de manera imperativa: «Los laudos arbitrales no serán susceptibles de ningún otro recurso que no establezca dicha Ley, sin que el mencionado cuerpo legal permita en dicho proceso la admisión del recurso de casación, por tal motivo, no procede y se niega el recurso de casación...»".

13. A. PonCE MARTinez, "Notas sobre la cláusula compromisoria y sus efectos en la legislación Ecuatoriana”', en R. CAIvano, La Clausula Arbitral, Bogotá: Universidad de Rosario, 2011, p.452. 
interponer recursos de aclaración y ampliación, i) incluso el tribunal arbitral que conoció el caso se disuelve una vez que ha sido dictado el laudo y se han resuelto los recursos horizontales, ii) es conocido por un juez distinto (jurisdicción ordinaria) a aquel que dictó el laudo arbitral, iii) el juez que conoce la acción de nulidad no es jerárquicamente superior al tribunal arbitral, iv) el juez que conoce la acción de nulidad no revisa el fondo de la controversia arbitral sin embargo declara la nulidad o no de un laudo arbitral, v) el objeto de la controversia es distinto; y, vi) la acción de nulidad tiene su propio procedimiento.

Con base en lo expuesto, es posible concluir que la acción de nulidad tiene por objetivo que un juez perteneciente a la justicia ordinaria, independiente y sin ser jerárquicamente superior al árbitro o tribunal arbitral que dictó el laudo, declare que éste es nulo por haberse encontrado cualquiera de las causales de nulidad dispuestas en el artículo 31 de la Ley de Arbitraje y Mediación. Este juez no revisa el fondo de la controversia arbitral, sino que siguiendo un procedimiento especial que inicia con una demanda, dicta sentencia, reconociendo o no el derecho de la parte actora a que se declare nulo el laudo arbitral.

\section{Sobre los procesos de conocimiento}

La doctrina procesal ha generado una clasificación sobre los procesos, en donde los distingue por las distintas funciones o fines que persiguen. Los ha clasificado en declarativos (de condena, puros, declaración constitutiva, mixtos, genéricos o de conocimiento), de ejecución y cautelares. Los primeros buscan "la declaración de un derecho o responsabilidad o de la constitución de una relación jurídica [...]. En todos ellos el juez regula un conflicto singular de intereses, y determina quien tiene el derecho, es decir, el juez es quien ius dicit" 14 .En los de ejecución no se trata de "una pretensión discutida que implique la necesidad de declarar quién tiene razón, sino una pretensión cuya existencia aparece clara y determinada en el título que se aduce, pero que está insatisfecha, porque el obligado no ha cumplido su obligación correlativa"15. Los cautelares por su parte buscan "prevenir los daños que el litigio pueda acarrear o que puedan derivarse de una situación anormal"16.

14. H. Devis Echandia, Compendio de Derecho Procesal, Tomo I, Teoría General del Proceso", 7ma. edición, Bogotá: ABC, 1979, p. 144.

15. Ibídem.

16. Ibídem, p. 145 
Es necesario entonces ubicar a la acción de nulidad dentro de esta calificación, en consideración a su naturaleza asi, de la simple lectura de estas definiciones podemos concluir que la acción de nulidad no genera un proceso de ejecución pues en ella no se discute sobre la insatisfacción de un derecho cierto y preexistente y menos puede ser considerada un proceso cautelar ya que no busca que el juez disponga medidas urgentes para evitar que se viole o se intente violar el ejercicio de un derecho. Habiendo excluido los procesos de ejecución y cautelares, es pertinente analizar si constituye uno de conocimiento.

En la acción de nulidad se discute el derecho para que el laudo arbitral sea declarado nulo. En efecto, por un lado estará la parte que argumenta que el laudo arbitral está viciado de nulidad por haberse cumplido cualquiera de las causales establecidas en el artículo 31 de la Ley de Arbitraje y Mediación y por otro, la parte que considera que el laudo es válido en tanto en cuanto no se cumple ninguno de los requisitos contemplados en dichas causales. Estas posiciones son puestas en conocimiento del juez para que éste declare quién tiene el derecho en relación a la nulidad o validez del laudo arbitral. Es decir, existe un proceso judicial en que el juez decide y determina quién tiene la razón con base en los argumentos de las partes.

No creemos posible sostener que una acción de nulidad no es un proceso de conocimiento sobre la base de que en esta acción, el juez únicamente revisa si se cumplen o no las causales de nulidad del laudo y no el fondo de la causa. Estamos claros que efectivamente no lo hace, pero bajo ninguna lógica es posible argumentar que la acción de nulidad no es un proceso de conocimiento por esta razón. Todo lo contrario, el juez, al resolver sobre la nulidad o validez de un laudo arbitral está declarando un derecho en favor de una las partes, elemento esencial para determinar que la acción de nulidad constituye un proceso de conocimiento ${ }^{17}$.

17. Revisadas sentencias de la ex Corte Suprema, hoy Corte Nacional, hemos podido identificar que ésta ha resuelto que en casos relacionados con homologación de sentencias extranjeras, el juez debe decidir dicha homologación en juicio de conocimiento. Nos hemos permitido considerar estas decisiones pues al igual que en las acciones de nulidad en estos casos tampoco se revisa el fondo de la controversia y aun así, la Corte los ha considerado como procesos de conocimiento (ver Expediente de Casación 227, R.O. 378 de 27 de julio de 2001 y Expediente de Casación 223, R.O. Suplemento 537 de 4 de marzo de 2005). Esto demuestra que no es necesario revisar el fondo de la causa para determinar que un proceso es o no de conocimiento, pues conforme recoge una de las señaladas resoluciones: "Lo que va a ser motivo de análisis y examen, no es el litigio que da origen a la sentencia, sino la sentencia misma". 
En base a lo expuesto, creemos posible concluir que al existir la declaración del juez sobre el derecho de las partes en relación a la nulidad o validez de un laudo arbitral estamos frente a un proceso de conocimiento ${ }^{18}$.

\section{Sobre las decisiones de las Corte}

Tal como lo señalamos, las cortes provinciales han aceptado recursos de casación sobre sentencias dictadas en procesos de nulidad de laudos arbitrales. Sin embargo, la Corte Nacional de Justicia (sala de admisión) durante los últimos años, ha inadmitido recursos de casación sobre sentencias dictadas dentro de los señalados procesos.

En efecto la Corte [sala de admisión] ha sostenido que la acción de nulidad es:

i) Un recurso incidental del arbitraje pues no se constituye en un proceso en el que se declare la existencia o inexistencia de un derecho. La Sala de Admisión señala que la Corte:

No tiene competencia para conocer vía casación la acción de nulidad de un laudo arbitral, acción de nulidad que tiene como antecedente la vigencia de la decisión arbitral. Ello en razón de que sería ilógico creer que las partes, habiéndose sometido voluntariamente a una decisión arbitral, excluyendo por sí la vía jurisdiccional, ahora se quieran someter a esta vía para anular precisamente una secuela de un acto voluntario que no admite recurso alguno, pues la efectividad del laudo proviene del compromiso de las partes de acatarlo, que no es un proceso o juicio al tenor del Art. 57 del Código de Procedimiento Civil, por tanto la decisión carece de las características propias de una sentencia judicial, que a las que alude el Art. de la Ley de Casación. Entonces esta Sala considera que la impugnación de un laudo arbitral no es un asunto de conocimiento, en atención a lo prescrito en el inciso final del Art. 32 de la Ley de Mediación y Arbitraje. El arbitraje es un mecanismo de solución de conflictos de jurisdicción privada por terceras personas,

18. El Dr. S. ANdrade UbidiA en su libro, La Casación Civil en el Ecuador, p. 106, recoge el criterio de la Primera Sala de la ex Corte Suprema de Justicia, en relación a que la acción de nulidad constituye un proceso de conocimiento "por ser dictados por la Corte Superior y poner fin al litigio declarando el derecho (la validez o la nulidad del laudo arbitral)." 
que no tienen la calidad e investidura de los jueces de la jurisdicción común, por no ser designados por el poder público, sustrayéndolos de la jurisdicción común, previo sometimiento voluntario de las partes en tal decisión, y cuya existencia impide a la Función Judicial conocer de las cuestiones litigiosas sometidas al arbitraje. De ahí que el Art. 31 de la Ley de Mediación y Arbitraje estatuye la inapelabilidad del laudo arbitral, por lo que la decisión arbitral se torna irrevocable, y podrá obtenerse su ejecución forzada del mismo modo que las sentencias de última instancia, siguiendo la vía de apremio ${ }^{19}$.

ii) [...] un recurso incidente respecto del arbitraje al que se han sometido las partes, no es admisible el recurso de casación, tanto más (SIC) que la decisión que emita la Corte Provincial no resuelve sobre el asunto de fondo (es decir respecto de lo principal) materia del arbitraje, sino que se pronuncia sobre nulidades del laudo arbitral; es decir, sobre cuestiones de procedimiento ${ }^{20}$.

Así mismo, ha señalado que:

i) La competencia de la justicia ordinaria radica exclusivamente en conocer y resolver si en el proceso arbitral existen o no los motivos de nulidad alegados, más no como una vía para acceder a una instancia que revise integralmente la controversia resuelta por el laudo. Entonces, se debe estimar que los jueces ordinarios que conocen la acción de nulidad del laudo no declaran derechos, puesto que esta declaración de derecho la hicieron los árbitros al momento de dictar el laudo[... $]^{21}$.

ii) Los juicios de nulidad de laudo no son procesos de conocimiento, sino procedimientos sumarísimos en los que se analiza la legalidad del procedimiento adoptado por los árbitros ${ }^{22}$.

19. Juicio de Nulidad de Laudo Arbitral No. 168-2012.

20. Ibídem.

21. Juicio Sumario/Especial No. 17711-2015-0209.

22. Ibídem. 
Los criterios de la Corte podrían ser resumidos de la siguiente forma:

i) No podría considerarse a la acción de nulidad del laudo arbitral como un proceso de conocimiento pues no declara la existencia de un derecho, toda vez que nace a partir de un laudo emitido dentro de un proceso arbitral al que las partes se sometieron voluntariamente, es decir, la acción de nulidad es dependiente del proceso arbitral. Esta relación señala la Corte, se refleja inclusive en el hecho de que el laudo arbitral no puede ser objeto de impugnación alguna, lo cual también impediría que la resolución dictada dentro de proceso de nulidad de laudo arbitral pueda ser recurrida ${ }^{23}$.

ii) La acción de nulidad no es un proceso de conocimiento en tanto en cuanto no resuelve los asuntos de fondo discutidos en el proceso arbitral, aún más, la Corte señala que la declaración de derechos la hicieron los árbitros en el laudo arbitral y que consecuentemente no sería posible que tal declaración se de en la acción de nulidad.

iii) La acción de nulidad no es un proceso de conocimiento pues es un procedimiento sumarísimo en el que se revisa la legalidad del proceso arbitral.

$\mathrm{Al}$ respecto, es necesario señalar lo siguiente:

Con relación al punto i), la Corte no advierte que la acción de nulidad es un proceso que si bien surge a partir de la expedición de un laudo, es independiente del proceso arbitral. Las razones por las cuales consideramos la independencia de la acción de nulidad ya fueron expuestas en líneas anteriores. La voluntariedad para el sometimiento a arbitraje para resolver controversias es voluntario, este factor no puede servir de fundamento para determinar que la acción de nulidad no es un proceso de conocimiento.

23. Este criterio también ha sido expuesto por la Corte Constitucional en la sentencia No. 173-14-SEP-CC. Se lo ha hecho en los siguientes términos: "De tal forma, la acción de nulidad surge como consecuencia de las causales previstas en el artículo 31 respecto del laudo arbitral, lo cual no genera ni da lugar a considerar que la acción de nulidad es una acción independiente del laudo que tiene un trámite adicional al previsto en el artículo mencionado, ya que por el contrario surge de este, conforme lo determinado en la ley. Siendo así, la restricción impuesta en el artículo 30 -inapelabilidad laudo arbitral- genera un efecto directo también en la acción de nulidad, ya que caso contrario la ley hubiera establecido la facultad de recurrencia de la sentencia que resuelva dicha acción". 
La voluntariedad está en la decisión de las partes de someter sus controversias a arbitraje y éste como se ha señalado termina con la expedición del laudo. La posibilidad de interponer una acción de nulidad y las causales que harían posible su interposición están establecidas en la Ley además, como se mencionó, la acción de nulidad es independiente del proceso arbitral, su procedimiento es distinto, tiene un objeto distinto, es conocida por la justicia ordinaria, incluso su resolución puede ser impugnada.

En ese orden de ideas, tampoco creemos que tenga sustento el argumento en el cual se señala que la resolución expedida dentro de un proceso de nulidad de laudo arbitral no puede ser impugnable en la medida en que tampoco lo puede ser el laudo arbitral ${ }^{24} \mathrm{y}$ menos aún para el caso del recurso de casación, que se lo presenta en contra de una sentencia dictada en segunda instancia por la Sala de lo Civil de la Corte Provincial que pone fin a un proceso de conocimiento.

Como ya hemos dicho, hay una independencia entre el proceso arbitral y el de nulidad, en el primer caso, es clara la norma en señalar que el laudo arbitral es inimpugnable no cabe recurso alguno sobre él (salvo aclaración y ampliación), esto no implica de ninguna forma, que la resolución dictada por la justicia ordinaria con relación a la nulidad o validez del laudo deba seguir la misma disposición.

En la Ley de Arbitraje y Mediación no se señala absolutamente nada en relación a la posibilidad o imposibilidad de impugnar la resolución de la acción de nulidad, lo cual no puede servir de justificativo para aplicar la norma que expresamente señala tal prohibición para los laudos. Al contrario, siguiendo las propias disposiciones de la Ley de Arbitraje y Mediación que señalan que las normas del Código de Procedimiento Civil son supletorias a las primeras, así como a las normas constitucionales, no habría razón para sostener que no es posible recurrir de la resolución de la acción de nulidad ${ }^{25}$. La Corte Provincial de Pichincha parece seguir este criterio; en varios casos revisados, ha aceptado recursos de apelación y casación sobre resoluciones dictadas en procesos de nulidad.

\footnotetext{
24. La Corte Constitucional en sentencia No. 124-15-SEP-CC ha señalado: "No existe por tanto justificación para que los jueces provinciales hayan pretendido argumentar la inapelabilidad del laudo arbitral como razón suficiente para negar el recurso de casación planteado en contra de una providencia judicial expedida por una Sala de la Corte Provincial de Justicia de Pichincha."

25. Debo señalar que se ha discutido sobre la posibilidad de interponer un recurso de apelación sobre la resolución
} 
En cuanto al punto ii), no se refuta de ninguna forma que en el proceso arbitral se revisa el fondo del mismo y que en la acción de nulidad no se lo haga, pues queda claro que el objeto de esta última está limitado a las causales determinadas en el artículo 31 de la Ley de Arbitraje y Mediación. Sin embargo, bajo este argumento no se puede sostener que la acción de nulidad no constituye un proceso de conocimiento.

Durante su tramitación como se ha dicho, se discute el derecho de las partes a que se declare la validez o nulidad de un laudo arbitral, esta declaración efectuada por el juez que conoce la causa es justamente la que determina que esta acción constituya un proceso de conocimiento.

En lo que tiene que ver con el punto iii), la Corte parecería justificar que la acción de nulidad no es un proceso de conocimiento sobre la base de que su procedimiento es sumarísimo. Es decir se entendería que un proceso de conocimiento es tal, dependiendo del procedimiento que siga.

$\mathrm{Al}$ respecto, es preciso dejar claro que el procedimiento que se le da a una causa no necesariamente determina que el proceso sea o no de conocimiento. En efecto, no es posible afirmar que solo los juicios tramitados por la vía ordinaria o verbal sumaria son de conocimiento. La acción de nulidad tiene un trámite especial y sumarísimo y a pesar de ello es un proceso declarativo de derechos y consecuentemente de conocimiento.

dictada dentro de un proceso de nulidad de laudo arbitral. Según la posición que niega la posibilidad de recurrir una sentencia de nulidad de laudo arbitral esta posición no le serían aplicables las disposiciones de la Constitución ni las del Código de Procedimiento Civil. Conforme este último cuerpo normativo, mientras la ley no deniegue expresamente el recurso, se entiende que lo concede. Vale señalar que el Código Orgánico General de Procesos no contiene esta disposición, es más, señala expresamente que el recurso de apelación solo podrá interponerse cuando la ley expresamente lo conceda, lo cual daría a entender que si no lo hace entonces no se podría plantear dicho recurso. Si a esto le sumamos el criterio de la Corte Constitucional del Ecuador en el sentido de que "el acceso a instancias superiores o etapas de apelación o casación, no constituye per se un derecho absoluto aplicable a todo tipo de procesos y materias, ni mucho menos a la voluntad de las partes, [...] existe un ámbito sobre regulación de los recursos procesales que queda bajo competencia y determinación del legislador [...]". Dicho en otras palabras, la Corte Constitucional debe aclarar que no todo tipo de restricción a instancias o etapas procesales superiores (mediante recursos de apelación, casación o revisión) constituye per se una afectación al derecho al debido proceso en la garantía de defensa; la vulneración se produce cuando existiendo la posibilidad de acceder a una etapa o instancia superior a través de un recurso previsto en el ordenamiento jurídico, la autoridad judicial impide conceder a alguna de las partes procesales dicha impugnación por decisiones injustificadas o irrazonables". (Ver sentencia No. 124-15-SEP-CC de la Corte Constitucional), entonces podríamos llegar a la conclusión de que a partir de la vigencia del Código General de Procesos no cabría la posibilidad de interponer recursos de apelación sobre resoluciones dictadas en acciones de nulidad. 


\section{Consideraciones finales}

a) A pesar de lo expuesto en estas breves líneas, es posible llegar a la conclusión de que un debate que ya ha tenido varios años, aún no logra consolidar una posición unánime. Vemos que por un lado la Corte Provincial de Pichincha considera a la acción de nulidad de un laudo arbitral como un proceso de conocimiento y consecuentemente admite recursos de casación interpuestos sobres sus sentencias y por otro a la Corte Nacional (Sala de Admisiones) que no admite tales recursos pues considera que esta clase de acciones no constituyen procesos de conocimiento. Es preciso señalar que también hemos podido evidenciar varias sentencias de la Corte Nacional de algunos años atrás en los que se ha tramitado y resuelto recursos de casación interpuestos sobre resoluciones de acciones de nulidad. ${ }^{26}$ Por lo tanto, la posición de esta corte tampoco ha sido consistente a lo largo del tiempo.

b) Mientras no haya una verdadera definición en relación a la naturaleza de la acción de nulidad por parte de las cortes ecuatorianas, es muy probable que la discusión continúe por mucho tiempo más.

c) Podría plantearse la posibilidad de una reforma a la Ley de Arbitraje y Mediación particularmente al artículo 31, de la Ley de Arbitraje y Mediación sobre todo en lo que tiene que ver con el procedimiento que debe seguir la acción de nulidad. En esta reforma valdría dejar claro que sobre la resolución dictada por el Presidente de la Corte Provincial no cabe recurso alguno, lo cual, eliminaría cualquier discusión al respecto.

d) Es preciso señalar que mientras no haya una clara definición sobre este tema, los perjudicados son los usuarios del sistema arbitral, quienes, una vez concluido el procedimiento, que en varios casos toma más tiempo que el determinado en la ley, se enfrentan adicionalmente a litigios en la justicia ordinaria que duran varios años sin resolverse y que adicionalmente generan una incertidumbre toda vez que no existe tal definición.

26. Ver procesos signados con los números: 546-10, R.O. Suplemento 350, 18 de octubre de 2012, 292-07 R.O. Suplemento 356, 31 de octubre de 2012, 57-07 R.O. Suplemento 416, 25 de marzo de 2013, 113-06 R.O. Suplemento 542, 6 de marzo de 2009. 
e) Por otro lado, si bien el dejar claro, mediante una reforma a la ley, que no cabe recurso alguno sobre la resolución que dicte el presidente de la Corte Provincial, podría ser una solución a esta discusión, valdría la pena preguntarse si esta imposibilidad no dejaría en indefensión a la parte que se crea afectada por la decisión del señalado Presidente y que posibilidades tendría el usuario frente a esta situación ${ }^{27}$.

f) A partir de la entrada en vigencia del Código Orgánico General de Procesos, podría darse una solución a la discusión relacionada con la posibilidad de apelar la resolución de la acción de nulidad dictada por el presidente de la Corte Provincial. En efecto, el Código es claro en que este recurso procede siempre que la ley expresamente lo conceda. En tal virtud, al no estar establecida esta posibilidad en la Ley de Arbitraje y Mediación no cabría la apelación de dicha resolución. Sin embargo, queda abierta la duda sobre la posibilidad de plantear un recurso extraordinario de casación considerando que esta sentencia es dictada dentro de un proceso de conocimiento y es de última y única instancia.

27. Considero relevante para esta discusión revisar la Sentencia de la Corte Constitucional No. 124-15-SEP-CC, de 22 de abril de 2015 dentro de los casos No. 1279-11-EP y 1280-11-EP acumulados. 